2018

\title{
Rent-Seeking in the Classroom and Textbooks: Where are we after 50 Years
}

\author{
Joshua C. Hall \\ West Virginia University, jhall23@mail.wvu.edu \\ Josh Matti \\ West Virginia University, jomatti@mix.wvu.edu \\ Yang Zhou \\ West Virginia University, ygzhou@mix.wvu.edu
}

Follow this and additional works at: https://researchrepository.wvu.edu/econ_working-papers Part of the Public Economics Commons

\section{Digital Commons Citation}

Hall, Joshua C.; Matti, Josh; and Zhou, Yang, "Rent-Seeking in the Classroom and Textbooks: Where are we after 50 Years" (2018). Economics Faculty Working Papers Series. 3.

https://researchrepository.wvu.edu/econ_working-papers/3 


\section{WestVirginiaUniversity.}

Department of Economics

Working Paper Series

\section{Rent-Seeking in the Classroom and Textbooks: Where are we after 50 Years?}

Joshua Hall

Josh Matti

Amir Neto

Working Paper No. 18-08

This paper can be found at the College of Business and Economics Working Paper Series homepage: 


\title{
Rent-Seeking in the Classroom and Textbooks: Where are we after 50 Years?
}

\author{
Joshua Hall* \\ Josh Matti ${ }^{\dagger}$ \\ Amir Neto ${ }^{\ddagger}$
}

March 15, 2018

\begin{abstract}
In this paper we provide an overview of Tullock's work on rent-seeking in the area of economics education. After summarizing the basic rent-seeking model in both a domestic and international context, we conduct an analysis of undergraduate and graduate texts in public economics. We find a majority of undergraduate texts cover rent-seeking in depth, but two texts provide zero coverage. No graduate textbook surveyed mentions rent-seeking. We conclude by summarizing the economic education literature on rent-seeking, which can be divided into either classroom experiments or popular culture examples.
\end{abstract}

Keywords: Economics Education, Rent-Seeking

JEL Classification: A20, B20, D72

*Joshua Hall, Associate Professor of Economics, Department of Economics, College of Business and Economics, West Virginia University, 1601 University Ave, PO BOX 6025, Morgantown, WV 26506, email: joshua.hall@mail.wvu.edu.

${ }^{\dagger} \mathrm{PhD}$ Candidate, Department of Economics, College of Business and Economics, West Virginia University, 1601 University Ave, PO BOX 6025, Morgantown, WV 26506, email: jomatti@mix.wvu.edu.

${ }_{\ddagger}^{\ddagger}$ PhD Candidate, Department of Economics, College of Business and Economics, West Virginia University, 1601 University Ave, PO BOX 6025, Morgantown, WV 26506, email: amneto@mix.wvu.edu. 


\section{Introduction}

In the 50 years since the publication of Tullock's (1967) seminal article, it has been cited thousands of times (Mueller, 2016). As evidenced by citations, the influence of his work has extended into nearly all fields of economics and beyond (Durden et al., 1991). In this paper we attempt to catalog and assess how Tullock's work on rent-seeking has been incorporated into undergraduate and graduate textbooks. In addition, we summarize the literature on economic education that focuses on rentseeking so that teachers interested in incorporating this literature into their classrooms can do so.

Thus, this paper focuses is on the existence and treatment of rent-seeking in graduate and undergraduate public economics textbooks. The relative importance given to the subject, however, is dependent on the instructor. Nevertheless, the introduction of rent-seeking in textbooks is a first step to introducing the human behavior into the public economics discussion. In short, both the act of interest groups and the political process will generate inefficiency and lost welfare due to investments in rent-seeking.

What we do not do in this paper, however, is make the case for why rent-seeking should be included in textbooks and public economics classes. Perhaps, as scholars exposed to public choice at formative stages of our careers, this seems self-evident to us and does not need to be articulated. For those reading this paper who are not of the public choice school, however, it is important to briefly reflect on why rent-seeking should be well-represented in all textbooks, not just public sector textbooks. ${ }^{1}$ We can think of at least three reasons why students should be taught rent-seeking and its importance to the world around us. First, a large part of what economists do, especially in public economics courses, is focus on social inefficiency. Rent-seeking is

\footnotetext{
${ }^{1}$ We are heavily indebted to an insightful referee for the motivation and insights contained in this paragraph.
} 
clearly socially inefficient. Second, rent-seeking - in the broadest sense - is a pervasive feature of humanity. Demonstrating rent-seeking's pervasiveness can provide for students a more accurate and complete understanding of human motivation across different institutional settings. Finally, the discussion of rent-seeking and its importance highlights for students how economies became distorted away from a "free market economy."

We proceed in the following manner. Section 2 discusses Tullock's (1967) and Krueger's (1974) seminal papers on rent-seeking. We briefly sketch these models for two reasons. First, some readers might prefer to have a self-contained article to hand to a student or colleague teaching public economics for the first time. Second, Mueller (2016) notes that Krueger (1974) has more citations than Tullock's (1967) and therefore textbook discussions might cite her or follow her approach but not his. Section 3 and 4 present how rent-seeking is treated (or not) in undergraduate and graduate public economics textbooks, respectively. Section 5 reviews the economic education literature on rent-seeking, and Section 6 concludes.

\section{The Rent Seeking Model}

The two seminal papers on rent-seeking are Tullock (1967) and Krueger (1974). Combined these papers have over 8,000 citations (Mueller, 2016). While Tullock (1967) introduces the rent-seeking problem by discussing monopolies and tariffs, Krueger (1974) applies this concept in an international trade framework. Each author followed a different path to explain the emergence of rent-seeking and its consequences. Tullock (1967) uses a simple graphical approach while Krueger (1974) develops a formal model and present some comparative statics. In this section we summarize both presentations of the rent-seeking problem and the implication raised by both authors. 


\subsection{Tullock's Graphical Model}

Tullock (1967) discusses three problems in which rent-seeking behavior is likely to arise: tariffs, monopoly and theft. At first these three problems may seem unrelated, however they are connected through some underlying mechanisms: transfers, and inefficiency.

At first, tariffs, monopoly, and theft create transfers from one group to another group. For instance, tariffs would create a transfer from international to domestic producers; a monopoly would create transfers from consumers to producers; and theft from the robbed to the burglars. If the transfers were to be the only concern, in terms of social welfare this would not be a problem, as the overall social welfare would remain the same, however, this is not the case.

The biggest concern is the inefficiency. The three problems Tullock (1967) discusses will result in an inefficient use of resources which sums up to a substantial loss to welfare. As argued by the author, governments will not enact tariffs on their own, but instead they will do so given the pressure (or lobbying) from domestic producers. Similarly, a non-natural monopoly will be created only if firms invest in acquiring this "privilege". On the other hand, people who do not want to get robbed, would have to spend productive time defending their property rather than producing. These investments in the attempt of acquiring "privilege" or "protection", in other words, the rent-seeking activities, are the biggest loss to society. Tullock (1967) points out that these activities are hard to identify and measure.

Tullock (1980) lays out rent-seeking as a game problem and provides evidence of what would be the efficient level of rent-seeking and how much would be lost in rent-seeking investment. This paper, although not pointed out by Tullock (2003) as crucial in the development of the rent-seeking concept, has been widely used in rentseeking experiments (Dechenaux et al., 2015). A simple algorithm is used to calculate individual and total investments. We reproduce these equations below 


$$
\begin{aligned}
& P_{A}=R \frac{N-1}{N^{2}} \\
& P_{A}=R \frac{b}{b+1}
\end{aligned}
$$

where $P_{A}$ is the equilibrium investment, $R$ is the determinant of the steepness of the supply curve (or exponent), $N$ is the number of players, and $b$ is the bias weight.

Sherementa (2015) provides a more intuitive approach to this model such that $P_{A}$ can be understood as the agent's effort to get the rent and $R$ is the rent's prize. As noted by both authors, the effort is increasing in the value of the prize $(R)$ and decreasing in the number of players $(n)$, which is the so-called "discouragement effect". The intuition behind the bias weight is the differentiation of players instead of purely restricting their participation in the rent-seeking activity.

\section{$2.2 \quad$ Krueger's Model}

Although Tullock (1967) was published seven years earlier than Krueger (1974), the latter does not cite Tullock's work. Tullock (2003) discusses the development of the idea of rent-seeking and why it was easy for others to miss his 1967 paper until Krueger's (1974) paper was published. It was Krueger (1974) who introduced the term rent-seeking to the literature and is on the list of the twenty most influential AER papers of the first one hundred years of the journal (Arrow et al., 2011). ${ }^{2}$

One key difference between Tullock (1967) and Krueger (1974) is that the former

\footnotetext{
${ }^{2}$ In discussing the importance of Krueger's work, Arrow et al. (2011) note how influential her work has been in the field of development economics. While not a focus of our paper, we did survey all undergraduate and graduate economic development textbooks to see whether rent-seeking was covered and how extensively. Every economic development textbook discussed rent-seeking and its importance, usually in relation to corruption. Most, but not all texts, cite Krueger's seminal article, but no economic development textbooks mention Tullock. Our reading of the economic development texts suggests that rent-seeking is seen as much more important in economic development than public economics. We hope to explore the difference between the coverage of rent-seeking in public economics and economic development in a future paper, and we are grateful to an anonymous referee for suggesting this avenue of research.
} 
relies on a graphical approach with intuitive arguments, while the latter develops a simple mathematical model to show the rent-seeking problem. One commonality in the papers is the discussion of tariffs as a rent-seeking issue. However, while Tullock's work describes the problem in a developed society, Krueger focuses on developing economies, which is likely why it has subsequently contributed to a large literature on corruption and governance in development. Below we discuss the main features of Krueger's (1974) model, and leave for the interested reader to refer to the original paper for more detail.

The model set-up is a basic one. The economy produces only agricultural goods which are exported, while it imports consumption goods. The only input used is labor. Thus

$$
A=A\left(L_{A}\right) \quad A^{\prime}>0, A^{\prime \prime}<0
$$

where $A$ is output and $L_{A}$ is the labor employed in agriculture. The demand for imports $(M)$ depends on the price $\left(p_{M}\right)$ and income that is created by the level of output $(A)$

$$
M=M\left(p_{M}, A\right) \quad M_{p_{M}}<0, M_{A}>0
$$

The food consumption $(\mathrm{F})$ is what is not exported $(D)$, such that by definition $D=M$. Hence,

$$
F=A-M
$$

Lastly, the labor force supply is fixed and composed by labor in agriculture $\left(L_{A}\right)$, labor in distribution $\left(L_{D} \equiv k D\right)$ and labor in rent-seeking $\left(L_{R}\right)$ :

$$
\bar{L}=L_{A}+L_{D}+L_{R}
$$


Under free trade the following occur: $L_{R} \equiv 0$ and $A^{\prime}=\frac{p_{D}}{k}$. However, once import restrictions with competitive rent-seeking occur, we have $A^{\prime}=\frac{p_{D} M}{L_{D}+L_{R}}$. One implication of the introduction of rent-seeking is change in food consumption. Equation (7) refers to the free trade scenario and equation (8) to the rent-seeking one.

$$
\begin{gathered}
-d F=d M\left(k A^{\prime}+1\right)>1 \\
d F=d A=-A^{\prime} L_{R}<0
\end{gathered}
$$

Lastly, Krueger (1974) shows the total value of rents, $R$ :

$$
R=\frac{p_{D} \bar{M} L_{R}}{L_{D}+L_{R}}
$$

Overall, although Tullock $(1967,1980)$ and Krueger $(1974)$ show the rent-seeking problem using different tools, the conclusion is the same: the loss to welfare from rent-seeking is not only those of inefficiency. Rather, there is a larger loss resulting from the investment in lobbying to acquire the rent.

\section{Rent-seeking in Undergraduate Public Textbooks}

To assess the treatment of rent-seeking at the undergraduate level, we reviewed 6 prominent public economics textbooks aimed at the undergraduate market. The six textbooks are Rosen and Gayer (2013), Holcombe (2006), Hindriks and Myles (2006), Ulbrich (2013), Gruber (2016), and Hillman (2009). These textbooks were selected because they are among the most widely used and representative of undergraduate public economics textbooks. ${ }^{3}$

Coverage of rent-seeking is considered along two dimensions. First, we look at

\footnotetext{
${ }^{3}$ Calcagno (2015) provides an broad discussion of public finance textbooks and the extent to which they cover material at the core of public choice.
} 
prominence within the textbook. For example, does rent-seeking have a separate chapter? Second, we analyze the extent to which it is covered. Textbooks emphasizing rent-seeking will include a separate chapter or section on rent-seeking, contain rent-seeking in the glossary and table of contents, and include greater page coverage. Although two textbooks may be similar in their emphasis of rent-seeking, they may differ in how rent-seeking is covered. Thus, we also consider whether each textbook contains a mathematical, graphical, or definitional treatment. Additionally, we assess whether each textbook includes an example of rent-seeking and whether Tullock or Krueger is cited, reflecting whether the coverage includes references to the original literature. Lastly, we consider the extent to which each textbook highlights the importance of rent-seeking in society ${ }^{4}$. Table 1 contains information on the textbooks surveyed, authors, and coverage of rent-seeking.

As shown in Table 1, the majority of undergraduate public economics textbooks surveyed include rent-seeking. Although there are differences in both prominence and method of coverage among textbooks, a few common patterns emerge. Across textbooks, the definition for rent-seeking generally highlights its inefficiency. Resources are used unproductively rather than productively. One difference across definitions is whether rent-seeking is applied specifically to rents created by governments. For example, Rosen and Gayer (2013) define rent-seeking as "using the government to obtain higher than normal returns" (p. 123). Hillman (2009) also emphasizes governments in the definition of rent-seeking. Rents are private benefits that would not be generated through a market process but instead require government intervention. However, Hindriks and Myles (2006) focus on inefficiency rather than government intervention. They define rent-seeking as the "expenditure of resources to create a profitable opportunity that is ultimately damaging to society" (p. 337). In the discussion surrounding their definition, the emphasis is on the inefficiency of rent-seeking

\footnotetext{
${ }^{4}$ We are thankful for a helpful referee comment in pointing out this importance aspect of how rent-seeking it covered
} 
and operating inside the production possibilities frontier.

Table 1: Treatment of Rent Seeking in Undergraduate Textbooks

\begin{tabular}{|c|c|c|c|c|c|c|}
\hline Book & $\begin{array}{l}\text { Rosen } \\
\& \text { Gayer }\end{array}$ & Holcombe & $\begin{array}{l}\text { Hindricks } \\
\& \text { Myles }\end{array}$ & Ulbrich & Hillman & Gruber \\
\hline Separate Chapter & $\mathrm{x}$ & $\mathrm{x}$ & $\mathrm{y}$ & $\mathrm{x}$ & $\mathrm{x}$ & $\mathrm{x}$ \\
\hline Separate Section & $\mathrm{y}$ & $\mathrm{y}$ & NA & $\mathrm{x}$ & $\mathrm{x}$ & $\mathrm{x}$ \\
\hline Index & $\mathrm{y}$ & $\mathrm{y}$ & $\mathrm{y}$ & $\mathrm{x}$ & $\mathrm{y}$ & $\mathrm{x}$ \\
\hline Table of Contents & $\mathrm{y}$ & $\mathrm{y}$ & $\mathrm{y}$ & $\mathrm{x}$ & $\mathrm{x}$ & $\mathrm{x}$ \\
\hline Page Coverage & 3 & 4 & 32 & 0 & 17 & 0 \\
\hline Mathematical Treatment & $\mathrm{x}$ & $\mathrm{x}$ & $\mathrm{y}$ & $\mathrm{x}$ & $\mathrm{y}$ & $\mathrm{x}$ \\
\hline Graphical Treatment & $\mathrm{y}$ & $\mathrm{y}$ & $\mathrm{y}$ & $\mathrm{x}$ & $\mathrm{y}$ & $\mathrm{x}$ \\
\hline $\begin{array}{l}\text { Verbal Treatment } \\
\text { (definition given) }\end{array}$ & $\mathrm{y}$ & $\mathrm{y}$ & $\mathrm{y}$ & $\mathrm{x}$ & $\mathrm{y}$ & $\mathrm{x}$ \\
\hline Tullock Referenced & $\mathrm{x}$ & $\mathrm{y}$ & $\mathrm{y}$ & $\mathrm{x}$ & $\mathrm{y}$ & $\mathrm{x}$ \\
\hline Krueger Referenced & $\mathrm{x}$ & $\mathrm{y}$ & $\mathrm{y}$ & $\mathrm{x}$ & $\mathrm{x}$ & $\mathrm{x}$ \\
\hline Example Given & $\mathrm{y}$ & $\mathrm{y}$ & $\mathrm{y}$ & $\mathrm{x}$ & $\mathrm{y}$ & $\mathrm{x}$ \\
\hline Importance Emphasized & $\mathrm{y}$ & $\mathrm{x}$ & $\mathrm{y}$ & $\mathrm{x}$ & $\mathrm{y}$ & $\mathrm{x}$ \\
\hline
\end{tabular}

Notes: Editions of surveyed texts are: Rosen and Gayer (2013), Holcombe (2006), Hindriks and Myles (2006), Ulbrich (2013), Hillman (2009), and Gruber (2016). y denotes "yes" and x denotes "no".

All textbooks including rent-seeking give a real-world example. A wide variety of examples exist across textbooks. Holcombe (2006) highlights professional organizations securing government regulations to restrict competition. Barbers, medical doctors, and real estate agents secure rents through government-imposed barriers to entry. Highlighting tariffs, Hindriks and Myles (2006) provide an example of a firm hiring lawyers to prevent imports from foreign competitors. Emphasizing the transfer nature of rent-seeking, Hillman (2009) gives the example of a productive and unproductive farmer. While the productive farmer engages in profit seeking, the unproductive farmer can engage in rent-seeking by lobbying the government to receive the property rights of the productive farmer.

Rosen and Gayer (2013) also emphasize farming by weaving the example of peanut farmers into their entire treatment of rent-seeking. Government licenses granted to peanut farmers is used in their graphical treatment, as an example immediately following the definition of rent-seeking, and as a way of understanding why rent-seeking 
continues to exist despite being socially inefficient. Peanut farmers expend resources to maintain a system of licenses to restrict peanut supply leading to monopoly pricing. This process leads not only to the deadweight loss of fewer mutually beneficial peanut trades but also the deadweight loss of rent-seeking. However, Rosen and Gayer (2013) explain that despite the social inefficiency rent-seeking remains because the benefits are concentrated among a few peanut farmers while the costs are dispersed across society. Every undergraduate text including rent-seeking provides an example, as these examples seem to be a natural way of solidifying student understanding of the definition of rent-seeking and a way to motivate the graphical treatment.

These examples may also be a substitute for more rigorous discussion of rentseeking models. For while examples of rent-seeking are common in undergraduate texts, mathematical treatments of rent-seeking are not. Only the advanced undergraduate texts of Hillman (2009) and Hindriks and Myles (2006) include math. Hillman (2009) starts with a Tullock contest function and ends with a demonstration of how rent dissipation varies with the number of players. Hindriks and Myles (2006) build the model by considering a prize to be won between two competitors. They explore when there will be complete and partial rent dissipation and how the results change with free-entry and risk aversion.

The ease of a graphical illustration may be a reason for why undergraduate texts are unlikely to include a mathematical treatment of rent-seeking. Each undergraduate text surveyed that includes rent-seeking also includes a graphical treatment. The graphical treatment builds upon an illustration that students are already familiar with- the deadweight loss of monopoly. In a straightforward way, the texts are able to show that the full deadweight loss to society includes not only the Harberger triangle but also the area containing monopoly profits. The most substantive treatment of the true deadweight loss is given in Hindriks and Myles (2006) as they include a discussion of real-world estimates. They not only mention that overall welfare loss from rent- 
seeking is between 4 and 13 percent of gross corporate product but also provide an example from the US Federal Communications Commission. In their allocation of 643 regional cell phone licenses, there were approximately 320,000 contestants with the total costs from all applications around $\$ 400$ million.

A majority of undergraduate textbooks covering rent-seeking do include a discussion of its importance, although in unique ways. Hillman (2009) reflects broadly, considering how rent-seeking can pervade a society's culture. Hindriks and Myles (2006) cite empirical estimates for the social cost of rent-seeking. Additionally, they highlight the prevalence of lobbyists and how at least 40,000 people in the United States are employed in positions that contribute no net value to society. Similar to Hindriks and Myles (2006), Rosen and Gayer (2013) also emphasize lobbying when considering the importance of rent-seeking. Although lobbyists bring no value to society, their salaries are often over a million dollars. The only undergraduate textbook including rent-seeking but lacking a discussion of its importance is Holcombe (2006). One explanation for the lack of coverage is that Holcombe (2006) appears to be written so as to be timeless. With no current empirical estimates, Holcombe (2006) naturally does not include a discussion of its importance. There are many ways that a topic can be considered important, and the undergraduate textbooks that consider rent-seeking generally include a unique discussion of why rent-seeking matters for a society.

While rent-seeking has permeated most undergraduate textbooks, the concept is not covered at all in Ulbrich (2013) and Gruber (2016). Both textbooks are public finance texts, not public economics books, which might explain part of the lack of coverage of rent-seeking. Both texts, however, are about the practice of public finance, and thus ultimately are about improving public sector outcomes. An understanding of rent-seeking and how it affects efficiency would seem to be at the core of improving public policy and thus the exclusion of rent-seeking is problematic. 


\section{Rent-Seeking in Graduate Public Textbooks}

We surveyed the six most prominent graduate textbooks in the field of public economics. The six textbooks are: Laffont (1988), Myles (1995), Kaplow (2011), Salanie (2011), Tresch (2015), and Atkinson and Stiglitz (2015). While rent-seeking is wellrepresented among the undergraduate texts surveyed, we found zero coverage of rentseeking in graduate public economics textbooks. Instead of identifying the different ways that rent-seeking is covered in graduate textbooks, this section instead explores possible reasons for why graduate textbooks do not discuss rent-seeking at all.

One possibility is that the rent-seeking model is not amenable to theoretical work. However, this is an unlikely explanation because there is a voluminous literature on theoretical models of rent-seeking with multiple areas of extension. A few early extensions include risk averse rent-seekers (Hillman and Katz, 1984), uncertain rents (Jadlow, 1985), non-identical sharing rules (Nitzan, 1991), and rent-seeking for pure

public goods (Katz et al., 1990). New theoretical rent-seeking papers are continuing to be published, such as new variants of incomplete information in rent-seeking contests (Wasser, 2013) and optimal taxation (Rothschild and Scheuer, 2016). Rent seeking models have and continue to be applied across a wide range of settings, suggesting that the reason for a lack of rent-seeking in graduate textbooks is not due to a lack of theoretical work related to rent-seeking.

While the theoretical literature on rent-seeking is large, empirical studies of rentseeking are less common as measuring rent-seeking is difficult. Thus, a lack of empirical work could explain why rent-seeking is not included in graduate texts. Despite the empirical difficulties, as surveyed in Del Rosal (2011), there are dozens of empirical rent-seeking studies. However, the measures of rent-seeking employed are defined in ad hoc and arguably imperfect ways. One common way, as in Laband and Sophocleus (1988), is to proxy for rent-seeking by the number of lawyers in a country as lawyers are key players in rent-seeking markets. A novel approach by Sobel and Garrett 
(2002) is to define rent-seeking as having an excess proportion of business activity related to rent-seeking across capital cities in the United States. Empirical evidence for rent-seeking remains scant and relies upon imperfect measures of rent-seeking. To the extent that graduate textbooks focus on core models with clear empirical applications, rent-seeking models are unlikely to be included.

The lack of rent-seeking coverage in graduate public textbooks might overstate the extent to which Tullock (1967) is not covered in graduate public economics courses. Most doctoral courses are paper driven, not book driven. Graduate syllabi typically include links to seminal articles that are covered in class, while graduate public textbooks seem to be primarily used as reference documents or in masters level courses. ${ }^{5}$

\section{Rent Seeking and Economic Education}

The instructor desiring to expose her students to the concept of rent-seeking has a number of options depending on the course and preparation of the students. One of the current authors, for example, would have his intermediate microeconomics students read Tullock (1967) during the section of the course on monopoly. Principles instructors, of course, are free to utilize the textbooks and examples described in Section 3. Or they can develop their own classroom example that would be of interest to students, such as the textbook market, as illustrated by Pecorino (2006). Our view, following Herbert Spencer, is that it takes varied iterations to get concepts to stick with students. For those looking for multiple and varied examples that allow for both repetition of concepts but variety, there exist a number of papers and materials in the economic education literature to assist. This literature can be broken down into two types: classroom experiments and media/popular culture. We briefly discuss each in

\footnotetext{
${ }^{5}$ At the urging of an insightful referee, we looked at the course offerings and publicly available syllabi for top programs in economics. Given the nature of academic placements, graduates of these programs will likely be those teaching future faculty. We could find no evidence of rent-seeking being explicitly covered in graduate public courses, at least among top 20 schools in economics.
} 
turn.

\subsection{Classroom Experiments}

The rise of experimental economics as a field in economics has led to a rise in use of experiments as a teaching tool. Holt (1999) provides a good introduction to the history of experiments in the classroom and issues related to conducting them. Goeree and Holt (1999) describes a simple classroom exercise that illustrates rent-seeking and the dissipation of rents. They urge instructors to put the exercise into a specific economic context, so as to help students with understanding and facilitate discussion. The context used in Goeree and Holt (1999) is the auctioning off of regional cellular telephone licenses by the US Federal Communications Commission, although their instructions can be adapted to a variety of other contexts.

The game described by Goeree and Holt (1999) involves four variations of an auction of a telephone license worth $\$ 16,000$. The license is awarded by lottery. The class is divided into four groups, each endowed with $\$ 100,000$. Each team can purchase an opportunity to win the telephone license for $\$ 3,000$. Up to thirteen opportunities can be purchased a round and the described game lasts three rounds. While students are initially focused on which team earned the most, post-game discussion is easily channeled towards the concept of rent dissipation. If more than five $\$ 3,000$ "lottery" tickets are purchased in total by the four teams in a round then the total value of the rent is dissipated. Goeree and Holt (1999) includes three variations on the game that illustrate different aspects of the problem, such as decreasing the amount of each "ticket" to $\$ 1,000$, which tends to encourage more rent-seeking attempts.

The Goeree and Holt (1999) game is straightforward and, given the team nature of the exercise, can easily be adapted to classrooms of different sizes. Individuals not desiring to spend an entire class on the game can just do one round, while the different variants allow the exercise to be extended in a way that provides ample 
information for subsequent discussion and reflection by students on the incentives facing individuals in a rent-seeking game. ${ }^{6}$ Bischoff and Hofmann (2002) and Strow and Strow (2006) provide additional modification and variations on Goeree and Holt (1999). In particular, new instructors will find the preparation information in Strow and Strow (2006) to be very helpful.

\subsection{Media and Popular Culture}

In the last decade economics education journals have been filled with examples of how to teach economics using examples from popular culture such as television (AlBahrani et al., 2016). Many of these papers provide examples of rent-seeking in the context of specific movies and television shows. Probably the best example is Mateer and Stephenson (2011). In this article they provide examples (with specific timing) from five movies that can be used to illustrate rent-seeking in different contexts. For example, a scene suggested from 1992's The Distinguished Gentlemen shows lobbyists expending resources on sponsoring a fundraising event for the fictional Rep. Johnson (Eddie Murphy). Mateer and Stephenson (2015) expand on this list with two more examples, including one from the Academy Award nominated film Dallas Buyers Club.

Podemska-Mikluch et al. (2016) discuss rent-seeking using examples from Harry Potter. Gillis and Hall (2010) provides an example from The Simpsons regarding market power and rent-seeking to keep a monopoly that would fit in well with a discussion of Tullock's (1967) paper and why he wrote it. More The Simpsons examples that can be used to illustrate rent-seeking can be found in Considine (2006) and Hall (2014). Not unsurprisingly, the television show Parks and Recreation, which focuses on the parks department of a small Indiana town, provides multiple examples of rent-seeking as detailed by Conaway and Clark (2015).

\footnotetext{
${ }^{6}$ Shughart (2015) provides an excellent discussion of conducting a one round all-pay auction in his masters-level public choice class.
} 


\section{Conclusion}

With two exceptions, in the fifty years since the publication of Tullock (1967), rentseeking has become standard in undergraduate public economics textbooks. Fike and Gwartney (2015) show that is also true for principles textbooks, with rent-seeking covered in nearly all major principles textbooks except for a couple of outliers. ${ }^{7}$ As the expansive title of Tullock's (1967) article suggest, rent-seeking is pervasive, although difficult to quantify in many situations. For that reason, much like narratives about how individuals in markets help move the market to a new equilibrium as the result of their actions, economists writing in the area of economic education have turned to experiments and examples drawn from popular culture to help illustrate rent-seeking in action.

\section{References}

Al-Bahrani, A., Holder, K., Patel, D., and Sheridan, B. J. (2016). The great digital divide: Using popular media to teach economics. Journal of Economics and Economic Education Research, 17(2):105.

Arrow, K., Bernheim, B. D., Feldstein, M. S., McFadden, D., Poterba, J., and Solow, R. (2011). 100 years of the american economic review: The top 20 articles. American Economic Review, 101(1):1-8.

Atkinson, A. B. and Stiglitz, J. E. (2015). Lectures on Public Economics. Princeton University Press, Princeton, NJ.

Bischoff, I. and Hofmann, K. (2002). Classroom game on the theory of rent seeking: Some practical experience. Southern Economic Journal, 69(1):195-199.

Calcagno, P. T. (2015). Teaching public choice economics in a public finance course. Journal of Economics and Finance Education, 14(2):23-33.

\footnotetext{
${ }^{7}$ An insightful referee asked us if any of the introductory textbooks mentioned rent-seeking when talking about monopolies or tariffs. While we did not have access to the full texts the intro textbooks discussed in Fike and Gwartney (2015), we read the treatment of monopoly and tariffs for the textbooks of Gwartney et al. (2018), Krugman and Wells (2012), Mankiw (2014), and Hubbbard and O'Brien (2017). With the exception of Gwartney et al. (2018), none of these texts discuss rent-seeking when talking about monopolies or tariffs. Gwartney et al. (2018) mentions rent-seeking expenditures possibly exceeding monopoly profit.
} 
Conaway, L. B. and Clark, C. (2015). Swansonomics: Using Parks and Recreation to teach economics. Journal of Economics and Finance Education, 14(1):41-68.

Considine, J. (2006). The simpsons: Public choice in the tradition of Swift and Orwell. The Journal of Economic Education, 37(2):217-228.

Dechenaux, E., Kovenock, D., and Sheremeta, R. M. (2015). A survey of experimental research on contests, all-pay auctions and tournaments. Experimental Economics, 18(4):609-669.

Del Rosal, I. (2011). The empirical measurement of rent-seeking costs. Journal of Economic Surveys, 25(2):298-325.

Durden, G. C., Ellis, L. V., and Millsaps, S. W. (1991). Gordon Tullock: His journal and his scholarship. Public Choice, 71(3):171-196.

Fike, R. and Gwartney, J. (2015). Public choice, market failure, and government failure in principles textbooks. Journal of Economic Education, 46(2):207-218.

Gillis, M. T. and Hall, J. (2010). Using The Simpsons to improve economic instruction through policy analysis. The American Economist, 55(1):84-92.

Goeree, J. K. and Holt, C. A. (1999). Classroom games: Rent-seeking and the inefficiency of non-market allocations. Journal of Economic Perspectives, 13(3):217-226.

Gruber, J. (2016). Public Finance and Public Policy. Macmillan, New York, 5 edition.

Gwartney, J. D., Stroup, R. L., Sobel, R. S., and Macpherson, D. A. (2018). Economics: Private and Public Choice. Cengage Learning, Boston.

Hall, J. (2014). Homer Economicus: The Simpsons and Economics. Stanford University Press, Palo Alto, CA.

Hillman, A. L. (2009). Public Finance and Public Policy: Responsibilities and Limitations of Government. Cambridge University Press, Cambridge, 2 edition.

Hillman, A. L. and Katz, E. (1984). Risk-averse rent seekers and the social cost of monopoly power. Economic Journal, 94(373):104-110.

Hindriks, J. and Myles, G. D. (2006). Intermediate Public Economics. MIT Press, Cambridge, MA.

Holcombe, R. G. (2006). Public Sector Economics: The Role of Government in the American Economy. Prentice Hall, Upper Saddle River, NJ.

Holt, C. A. (1999). Teaching economics with classroom experiments: A symposium. Southern Economic Journal, 65(3):603-610.

Hubbbard, R. G. and O'Brien, A. P. (2017). Microeconomics. Pearson, Boston. 
Jadlow, J. (1985). Monopoly rent seeking under conditions of uncertainty. Public Choice, 45(1):73-87.

Kaplow, L. (2011). The Theory of Taxation and Public Economics. Princeton University Press, Princeton, NJ.

Katz, E., Nitzan, S., and Rosenberg, J. (1990). Rent-seeking for pure public goods. Public Choice, 65(1):49-60.

Krueger, A. O. (1974). The political economy of the rent-seeking society. American Economic Review, 64(3):291-303.

Krugman, P. and Wells, R. (2012). Microeconomics.

Laband, D. N. and Sophocleus, J. P. (1988). The social cost of rent-seeking: First estimates. Public Choice, 58(3):269-275.

Laffont, J.-J. (1988). Fundamentals of Public Economics. MIT Press, Cambridge, MA.

Mankiw, N. G. (2014). Principles of microeconomics. Cengage Learning, Boston.

Mateer, G. D. and Stephenson, E. F. (2011). Using film clips to teach public choice economics. Journal of Economics and Finance Education, 10(1):28-36.

Mateer, G. D. and Stephenson, E. F. (2015). Using film clips to teach public choice economics: Take two. Journal of Economics and Finance Education, 14(2):76-85.

Mueller, D. C. (2016). Gordon Tullock: Economic gadfly. Constitutional Political Economy, 27(2):112-123.

Myles, G. D. (1995). Public Economics. Cambridge University Press, Cambridge.

Nitzan, S. (1991). Rent-seeking with non-identical sharing rules. Public Choice, $71(1): 43-50$.

Pecorino, P. (2006). Rent seeking: A textbook example. The Journal of Economic Education, 37(3):331-339.

Podemska-Mikluch, M., Deyo, D., and Mitchell, D. T. (2016). Public choice lessons from the wizarding world of Harry Potter. Journal of Private Enterprise, 31(1):57.

Rosen, H. and Gayer, T. (2013). Public Finance. McGraw-Hill Higher Education, New York, 10 edition.

Rothschild, C. and Scheuer, F. (2016). Optimal taxation with rent-seeking. The Review of Economic Studies, 83(3):1225-1262.

Salanie, B. (2011). The economics of taxation. MIT Press. 
Sherementa, R. (2015). Behavioral dimensions of contests. In Congleton, R. and Hillman, A., editors, Companion to the Political Economy of Rent Seeking, chapter 10, pages 150-164. Edward Elgar, Northampton, MA.

Shughart, W. F. (2015). Teaching public choice at the master's level. Journal of Economics and Finance Education, 14(2):5-22.

Sobel, R. S. and Garrett, T. A. (2002). On the measurement of rent seeking and its social opportunity cost. Public Choice, 112(1):115-136.

Strow, B. K. and Strow, C. W. (2006). A rent-seeking experiment for the classroom. The Journal of Economic Education, 37(3):323-330.

Tresch, R. W. (2015). Public finance: A Normative Theory. Academic Press, Cambridge, MA.

Tullock, G. (1967). The welfare costs of tariffs, monopolies, and theft. Western Economic Journal, 5(3):224-232.

Tullock, G. (1980). Efficient rent seeking. In Buchanan, J., Tollison, R., and Tullock, G., editors, Toward a Theory of the Rent-Seeking Society. Texas A\&M University Press, College Station.

Tullock, G. (2003). The origin rent-seeking concept. International Journal of Business and Economics, 2(1):1-8.

Ulbrich, H. H. (2013). Public Finance in Theory and Practice. Routledge, London, 2 edition.

Wasser, C. (2013). Incomplete information in rent-seeking contests. Economic Theory, $53(1): 239-268$. 